Article

\title{
A Multi-Region Magnetoimpedance-Based Bio-Analytical System for Ultrasensitive Simultaneous Determination of Cardiac Biomarkers Myoglobin and C-Reactive Protein
}

\author{
Zhen Yang 1,2,*(D), Huanhuan Wang ${ }^{1,2}$, Pengfei Guo ${ }^{1,2}$, Yuanyuan Ding ${ }^{1,2}$, Chong Lei ${ }^{3}$ \\ and Yongsong Luo ${ }^{1,2}$ \\ 1 School of Physics and Electronic Engineering, Xinyang Normal University, Xinyang 464000, China; \\ 13323978535@163.com (H.W.); guopengfei2010@126.com (P.G.); m15037680221@16.com (Y.D.); \\ eysluo@163.com (Y.L.) \\ 2 Key Laboratory of Microelectronics and Energy of Henan Province, Xinyang Normal University, \\ Xinyang 464000, China \\ 3 Department of Micro/Nano Electronics, School of electronic information and electrical engineering, \\ Shanghai Jiao Tong University, Dongchuan Road 800, Shanghai 200240, China; leiqhd@sjtu.edu.cn \\ * Correspondence: zhc025@alumni.sjtu.edu.cn; Tel.: +86-376-6391731
}

Received: 12 April 2018; Accepted: 28 May 2018; Published: 1 June 2018

\begin{abstract}
Cardiac biomarkers (CBs) are substances that appear in the blood when the heart is damaged or stressed. Measurements of the level of CBs can be used in course of diagnostics or monitoring the state of the health of group risk persons. A multi-region bio-analytical system (MRBAS) based on magnetoimpedance (MI) changes was proposed for ultrasensitive simultaneous detection of CBs myoglobin $(\mathrm{Mb})$ and C-reactive protein (CRP). The microfluidic device was designed and developed using standard microfabrication techniques for their usage in different regions, which were pre-modified with specific antibody for specified detection. Mb and CRP antigens labels attached to commercial Dynabeads with selected concentrations were trapped in different detection regions. The MI response of the triple sensitive element was carefully evaluated in initial state and in the presence of biomarkers. The results showed that the MI-based bio-sensing system had high selectivity and sensitivity for detection of CBs. Compared with the control region, ultrasensitive detections of $\mathrm{CRP}$ and $\mathrm{Mb}$ were accomplished with the detection limits of $1.0 \mathrm{pg} / \mathrm{mL}$ and $0.1 \mathrm{pg} / \mathrm{mL}$, respectively. The linear detection range contained low concentration detection area and high concentration detection area, which were $1 \mathrm{pg} / \mathrm{mL}-10 \mathrm{ng} / \mathrm{mL}, 10-100 \mathrm{ng} / \mathrm{mL}$ for CRP, and $0.1 \mathrm{pg} / \mathrm{mL}-1 \mathrm{ng} / \mathrm{mL}, 1 \mathrm{n} / \mathrm{mL}-80 \mathrm{ng} / \mathrm{mL}$ for $\mathrm{Mb}$. The measurement technique presented here provides a new methodology for multi-target biomolecules rapid testing.
\end{abstract}

Keywords: myoglobin; C-reactive protein; Dynabeads; magnetoimpedance; microfluidic device

\section{Introduction}

Measurements of the level of cardiac biomarkers (CBs) is important when the heart is damaged or stressed, especially in the case of cardiovascular disease (CVD) risk [1,2]. Among various kinds of cardiac biomarkers, C-reactive protein (CRP) is a most important biomarker for CVD risk. The level of CRP can rise from a normal level of less than $5 \mathrm{mg} / \mathrm{L}$ to above $100 \mathrm{mg} / \mathrm{L}$ after acute inflammatory stimulus [3]. Myoglobin $(\mathrm{Mb})$ is one of the early biomarker levels which increases sharply from $90 \mathrm{pg} / \mathrm{mL}$ to $250 \mathrm{ng} / \mathrm{mL}$ within $90 \mathrm{~min}$ after acute myocardial infarction (AMI), playing a major role in urgent diagnosis of CVD [4-6]. More and more researchers have attempted to apply different types of 
biosensors to detect the levels of two biomarkers [7-11]. Fluorescence-linked immunosorbent assay was widely used for detection of CBs; however, it is frequently used in in vitro diagnosis and complicated operation steps limit its application [12,13]. Immunosensors based on electrochemical impedance spectroscopy (EIS) usually use an immobilized recognition element (probe) to bind the target/analyte molecule selectively. However, the surface of the biosensors suffer from perturbations on the sensor surface that are influenced by different $\mathrm{pH}$, ionic strength and co-existing molecules in biological fluids. So, the sensitivity, specificity, and relevant range are affected [14,15]. Magnetic bio-detection based on giant magnetoimpedance was proposed long ago [16,17]. Magnetoimpedance (MI) is the change of total impedance of ferromagnetic-conducting sensitive elements under application of an external magnetic field [18-20]. Recently, different MI-based bio-sensing systems for micro-sized/nano-sized magnetic particles and single biomarker detection were designed and tested [21-28].

Despite the progress in medical diagnostics, CVD is considered to be the most common disease which occurs in middle age and elderly people, especially those over 50 years old [29]. The symptoms are complex and associated with more than one biomarker. Detection of a single cardiac biomarker is usually not sufficient for precise CVD diagnostics, due to the limited specificity [30]. Therefore, there is an urgent need for development of a simple, rapid, highly sensitive and inexpensive system for simultaneous detection of several cardiac biomarkers. The advantage of a microfluidic device (MFD) is that different biomarkers can be tested in various detection regions pre-modified with different specified antibodies, i.e. the development of multi-analyte immunoassay combined with a multi-region bio-analytical system (MRBAS) is a very important task [31-35]. The studies in recent years indicated that a higher MI effect can be reached in a multilayered structure and in thin films shaped as meanders [36-40]. Both high MI response and high sensitivity with respect to an applied magnetic field are the main factors for MI bio-sensing applications.

In this paper, we designed and tested the ultrasensitive bio-analytical MI-based system for simultaneous detection of CRP and $\mathrm{Mb}$, based on optimization of the structural parameters of the MI element. Immune reaction was performed in the MRBAS based on MI changes. The MI response of the sensitive element was measured in its initial state and in the presence of biomarkers. Compared with the control region, ultrasensitive and combined detection of CRP and Mb was accomplished in the different detection regions. The methodology presented here provides a vital basis for multi-analyte bio-magnetic detection like Troponin, Creatine Kinase-MB, alpha-fetoprotein (AFP) and carcinoembryonic antigen (CEA).

\section{Materials and Methods}

\subsection{Reagents and Instruments}

All the biological and chemical reagents used for the present study are listed in Table 1. For all experiments described here, deionized water was used. The MI multilayered sensitive element and Multi-region microfluidic devices (MR-MFD) were prepared by widely employed micro electromechanical system technology (MEMS) in National Key Laboratory (China). MI measurements were made using a special system based on a Hewlett-Packard 4194A Impedance analyzer (Agilent Technologies Inc., Palo Alto, CA, USA). The programmable syringe pump (PHD 4400 HPSI, Harvard Apparatus, Holliston, MA, USA) was connected with the MFD and adopted for injecting test samples. All measurements were made at room temperature. 
Table 1. Biological and chemical reagents.

\begin{tabular}{ccc}
\hline Solution & Detail & Company \\
\hline Mercaptopropionic acid & Concentration $20 \mathrm{mmol} / \mathrm{L}$ & Aladdin Chemistry Co. Ltd (Beijing, China) \\
EDC & Concentration $0.2 \mathrm{~mol} / \mathrm{L}$ & Aladdin Chemistry Co. Ltd (Beijingi, China). \\
NHS & Concentration $0.05 \mathrm{~mol} / \mathrm{L}$ & Shanghai Medpep Co. Ltd (Shanghai, China) \\
Mouse Mb \&CRP 1st antibody & Concentration $1 \mathrm{mg} / \mathrm{mL}$ & Linc-Bio Science Co. Ltd. (Shanghai, China) \\
BSA & $1 \%$ BSA, $0.2 \%$ tween 20 & Via-gene pro bio Technologies Co. Ltd. (Shanghai, China) \\
Human Mb \&CRP antigen & $0.1-100 \mathrm{pg} / \mathrm{mL}, 1-100 \mathrm{ng} / \mathrm{mL}$ & Linc-Bio Science Co. Ltd. (Shanghai, China) \\
$\mathrm{Mb} \& \mathrm{CRP} 2 \mathrm{nd}$ antibody & Concentration $1 \mathrm{mg} / \mathrm{mL}$ & Linc-Bio Science Co. Ltd. (Shanghai, China) \\
Dynabeads ${ }^{\circledR} \mathrm{C} 1$ & Concentration $10 \mu \mathrm{mg} / \mathrm{mL}$ & Invitrogen Co. Ltd. (Shanghai, China) \\
$\mathrm{NaOH}$ & Concentration $1 \mathrm{~mol} / \mathrm{L}$ & Pinghu Chemical Reagent (Pinghu, China) \\
$\mathrm{HCL}$ & Concentration $1 \mathrm{~mol} / \mathrm{L}$ & Sinpharm Chemical Reagent Co. Ltd. (Shanghai, China) \\
$\mathrm{PBS}$ & PH $=7.4$ & Medicago AB (Uppsala, Sweden) \\
$\mathrm{C}_{3} \mathrm{H}_{6} \mathrm{O} \quad \mathrm{C}_{2} \mathrm{H}_{5} \mathrm{OH}$ & $\mathrm{AR}$ & LingFeng Chemical Reagent Co. Ltd. (Shanghai, China) \\
\hline
\end{tabular}

\subsection{Microfabrication of MI Element and MR-MFD}

The meander-shaped MI element was designed for superior structural parameters, and the manufacturing process was presented in Figure S1, following our previous experiments described elsewhere [41]. The electrodeposited NiFe layer had good soft magnetic properties, which were similar to those previously studied in in our works [42,43]. Figure 1A shows the design diagram of MR-MFD. Two detection regions (CRP detection region $1 \& \mathrm{Mb}$ detection region 2), one blank control region and two inlets (sample and region buffer) were designed. The distance between any of two adjacent detection regions are $20 \mathrm{~mm}$ in order to minimize the magnetic interference between them. Each detection region contained a single rectangular gold film unit and possessed an area of $3 \times 5 \mathrm{~mm}^{2}$, and the control region possessed the same area without the gold film unit. The MR-MFD were fabricated based on SU-8 and polydimethylsiloxane (PDMS) materials by MEMS technology. The general view of the fabricated MI element is shown in Figure 1C. The MR-MFD containing the fluid reservoir and microfluidic pipeline were designed for sandwich immunoassay. Following is the step-by-step description of MR-MFD preparation:

1. Fabrication of gold layer: First a chromium adhesion layer $(\sim 60 \mathrm{~nm})$ was deposited on the glass wafer with a thickness of $1 \mathrm{~mm}$ at a rate of $1 \AA \mathrm{s}^{-1}$, followed by $\sim 240 \mathrm{~nm}$ of gold at a rate of 2-3 $\mathrm{A} \mathrm{s}^{-1}$ by a radio frequency sputtering system (LH-Z550, Shanghai, China).

2. Patterning of the gold film: A photoresist layer with a thickness of $10 \mu \mathrm{m}$ was spun onto the $\mathrm{Au}$ layer and afterwards patterned to several small MFD units through the mask.

3. Deleting the uncovered part of the gold layer: the uncovered part of the Au layer was removed by wet etching in the KI, $\mathrm{I}_{2}$ and $\mathrm{H}_{2} \mathrm{O}$ mixed solution for $45 \mathrm{~s}$.

4. Deleting the photoresist: The whole glass substrate with Au film was immersed in acetone solution for $25 \mathrm{~s}$.

5. SU-8 layers preparation: The SU-8 photoresist with a thickness of $500 \mu \mathrm{m}$ was spin coated on $\mathrm{Au}$ film, soft baked, patterned with a mask, and developed with an SU-8 developer. Then, the same thickness of the SU-8 photoresist was spun again, finally a $5 \times 3 \mathrm{~mm}^{2}$ rectangular microcavity with a depth of $1 \mathrm{~mm}$ was achieved. Figure 1B showed the SEM of gold nanofilm.

6. PDMS casting: The pre-polymer and the curing agent of PDMS were mixed in a 10:1 ratio by weight. After thermal coagulation, the PDMS can be obtained.

7. Bonding of the SU-8 with the PDMS: The surface-treated PDMS was tightly bound to the Su-8 surface and then opened the inlets and waste chamber. Figure $1 \mathrm{~A}$ (inset) shows the fabricated microfluidic device without PDMS. 


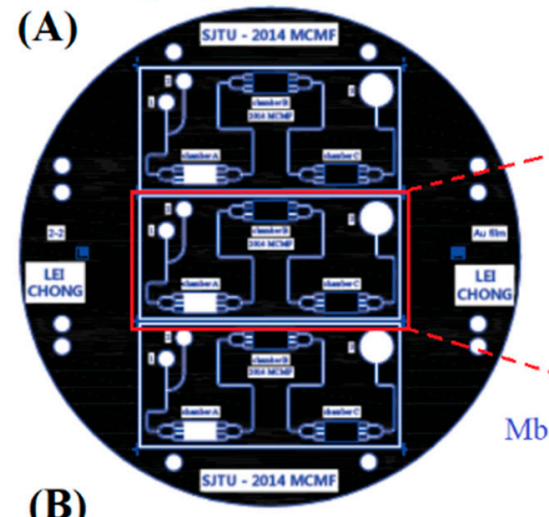

(B)

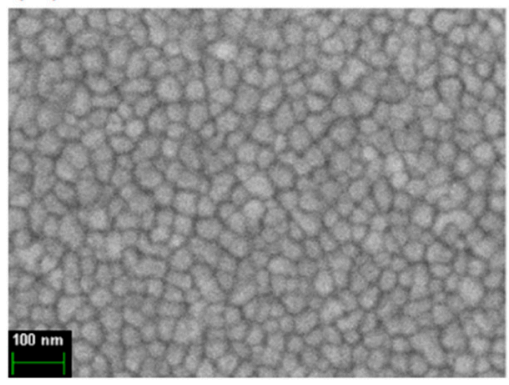

CRP Detection region " 1 "

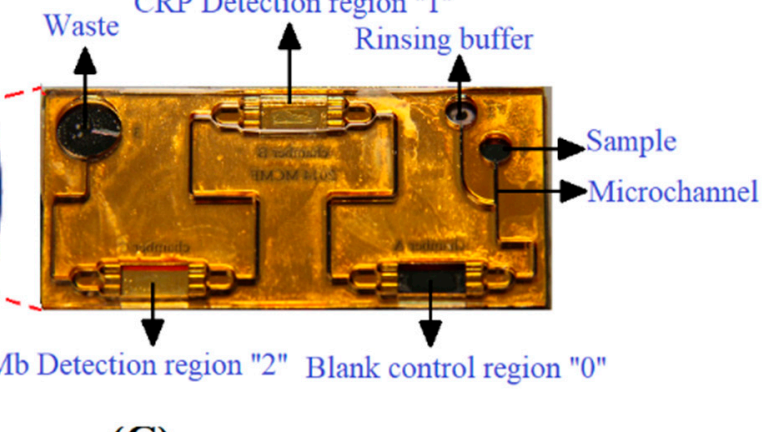

(C)

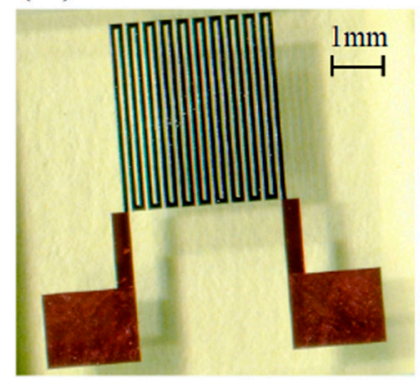

Figure 1. (A) The designed diagram of the microfluidic device, and the inset showing the photograph of the fabricated microfluidic device. (B) The Scanning Electron Microscopy image of the thin gold film.

(C) The fabricated multilayer MI element.

\subsection{Sandwich Immunoassay for Capturing $C B s$}

The detection regions were pre-modified through self-assembly and activation, prior to PDMS bonding. To achieve selectivity and improve the efficiency of detection, the detection regions 1 and 2 were surface modified with a mouse CRP monoclonal antibody or mouse Mb monoclonal antibody, respectively. The details for the self-assembling, activation and modification process can be found elsewhere [27]. After the surface modification, the detection regions were carefully rinsed with phosphate-buffered solution (PBS) prepared with deionized water. Afterwards, the detection regions were sealed with $100 \mu \mathrm{L}$ BSA solution (including $1 \%$ BSA, $0.2 \%$ tween 20 ) at $4{ }^{\circ} \mathrm{C}$ for $2 \mathrm{~h}$ and washed twice with PBS solution ( $\mathrm{PH}=7.4)$. The CRP and $\mathrm{Mb}$ antigen complexes with different concentrations $(1 \mathrm{pg} / \mathrm{mL}-100 \mathrm{ng} / \mathrm{mL}$ for CRP and $0.1 \mathrm{pg} / \mathrm{mL}-80 \mathrm{ng} / \mathrm{mL}$ for $\mathrm{Mb})$ were placed into the MR-MFD by a simple syringe pump. The complexes flowed through different regions in turn. Immunoassay time was as long as $20 \mathrm{~min}$, aiming to ensure an effective combination of antigen-antibody. Finally, The PBS solution was used for rinsing. Then, biotinylated CRP \& $\mathrm{Mb}$ polyclonal antibody $(10 \mu \mathrm{L}, 1 \mathrm{mg} / \mathrm{mL})$ mixed solution was injected into the MR-MFD and washed five times. Finally, Dynabeads suspension $(40 \mu \mathrm{L}, 10 \mu \mathrm{g} / \mathrm{mL})$ was injected. Dynabeads are polystyrene/iron oxide nanomaterials (superparamagnetic spheres) widely used for magnetic separation and biosensing [44-46]. After cultivating, washing and drying the whole double antibody immunoassay process was completed as shown in Figure 2B. 


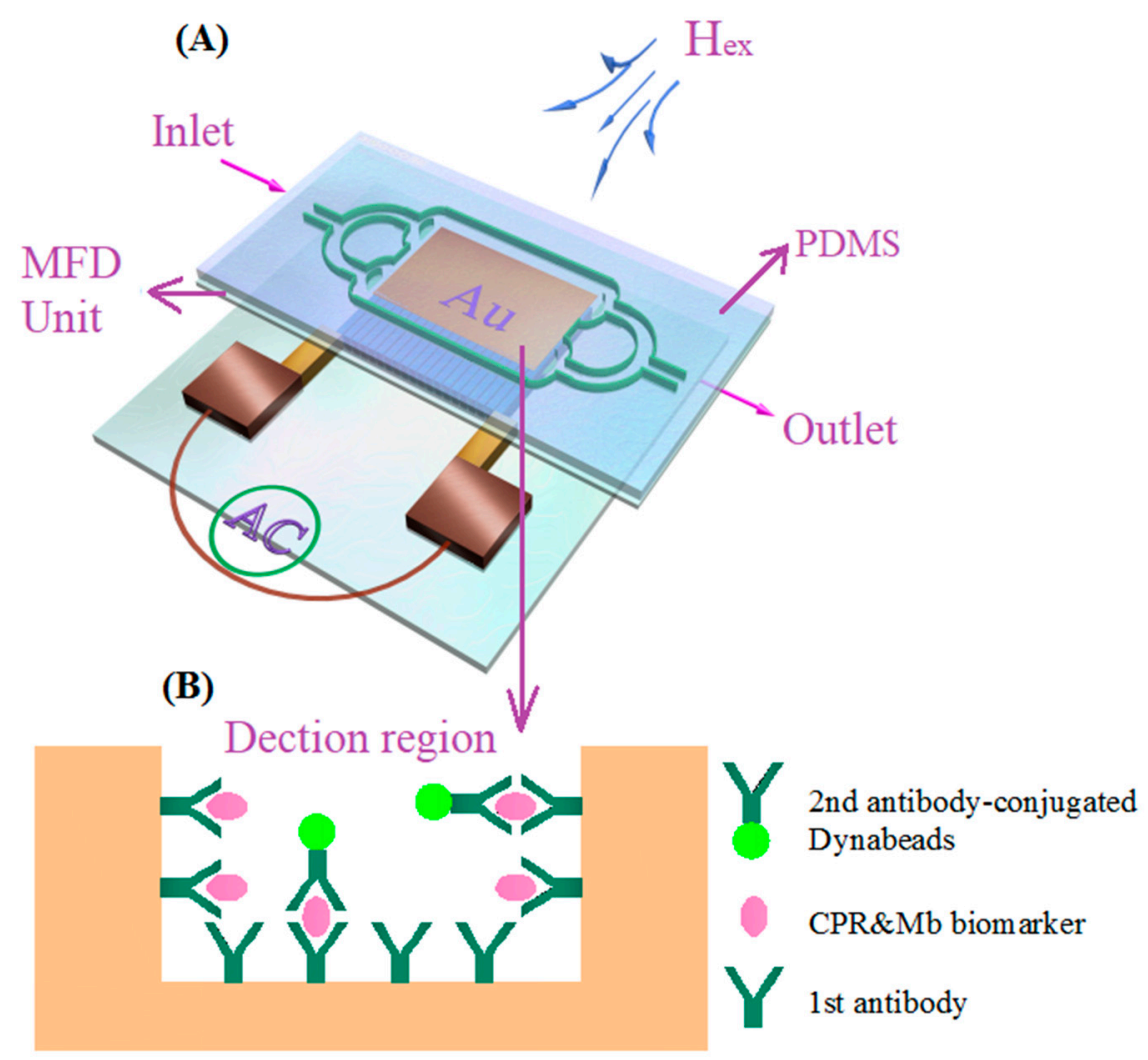

Figure 2. The principle diagram of detection for cardiac biomarkers using an MI sensitive element in the shape of the meander (A); general illustration of the biochemical part of the detection part (B).

\subsection{Determination of CBs Using MI-Based Bio-Analytic System}

The CRP and $\mathrm{Mb}$ antigen were mixed with the same concentration and volume (10 $\mu \mathrm{L})$ in all cases under consideration. Different detection regions modified by different antibodies would capture different CBs. First of all, the MI response of the thin film element located below the blank control region was measured in its initial state. The MI response of the thin film element located below the detection regions 1and 2 were measured in the presence of CBs. The fundamental principle for detection of Dynabead-labeled CBs is the detection of the stray fields $\left(\mathrm{H}_{\text {stray }}\right)$ of the Dynabeads. This is a similar principle as it was previously discussed in many cases of different magnetic biosensors [17,37-39]. When the MI element was moved to the bottom of the detection region of MR-MFD, the Dynabeads trapped in the MFD unit, located above the MI element as shown in Figure 2A, were magnetized by an external magnetic field $\left(\mathrm{H}_{\mathrm{ex}}: 0-120 \mathrm{Oe}\right)$ created by a pair of Helmholtz coils and they emitted a detectable $\mathrm{H}_{\text {stray }}$. The $\mathrm{H}_{\text {stray }}$ modified the partially overlapping magnetic field near the MI element and resulted in changes of transverse permeability and skin penetration depth; this lead to the altering of MI. The different concentrations of CBs flowing through the MR-MFD corresponds to the changes of MI. The advantages of this MI-based MRBAS is that the different MI responses in the varying regions reflect the content for $\mathrm{CRP}$ and $\mathrm{Mb}$, simultaneously. The effect of $\mathrm{H}_{\text {stray }}$ on $\mathrm{MI}$ is affected by the distance of the MR-MFD to the MI element; therefore, the thinnest glass wafer is selected to use as a substrate for MR-MFD fabrication. The MI ratios were calculated as follows:

$$
\text { MI ratio }=\frac{\Delta Z}{Z}=100 \times \frac{Z(H)-Z\left(H_{\max }\right)}{Z\left(H_{\max }\right)}
$$

where $H_{\max }=120$ Oe for orientation of the external magnetic field along the long side of the meander thin film elements. 


\section{Results and Discussion}

The maximum MI sensitivity of the fabricated sensitive element of about $22 \% \mathrm{Oe}^{-1}$ was obtained at $1.4 \mathrm{MHz}$ and 8.8 Oe field. Different antigen molecules were captured in different detection regions. The antigen molecules were combined with a certain number of magnetic beads. The beads captured in different detection regions were magnetized in varying degrees and behaved as a magnetic dipole producing stray fields $\mathrm{H}_{\text {stray }}$, disturbing the external magnetic field. Therefore, the original transverse permeability $\mu_{\mathrm{T}}$ of the MI sensitive element experiences a different resultant magnetic field $\mathrm{H}_{\mathrm{R}}=\mathrm{H}_{\mathrm{ex}}+\mathrm{h}_{\mathrm{AC}}+\mathrm{H}_{\text {stray }}\left(\mathrm{h}_{\mathrm{AC}}\right.$ was AC current magnetic field) and achieves a different value of field superposition giving rise to a different value in the MI ratio. The MI response quantitatively reflects the presence, content, or the absence of biomarkers.

Figure 3 shows the relationship between the MI responses and CRP concentrations $\left(\mathrm{C}_{\mathrm{CRP}}\right)$. The field dependences of the MI ratio for detecting different concentration of CRP are shown in Figures 2 and 3. Evidently, the MI ratios have been enhanced by distinct values on account of the CRP antigen conjugated with magnetic beads with different concentrations in the detection region 1 , from $1 \mathrm{pg} / \mathrm{mL}$ to $10 \mathrm{ng} / \mathrm{mL}$. It was worthwhile to note that the MI ratio increased from $195 \%$ (without CRP antigen) to $212 \%$ with increasing the concentration of the CRP antigen. For each concentration, independent measurement was performed 10 times under the same testing conditions. The relative standard deviation (RSD) is reasonable, as can be seen in Figure 3A; this indicates good precision.

(A)

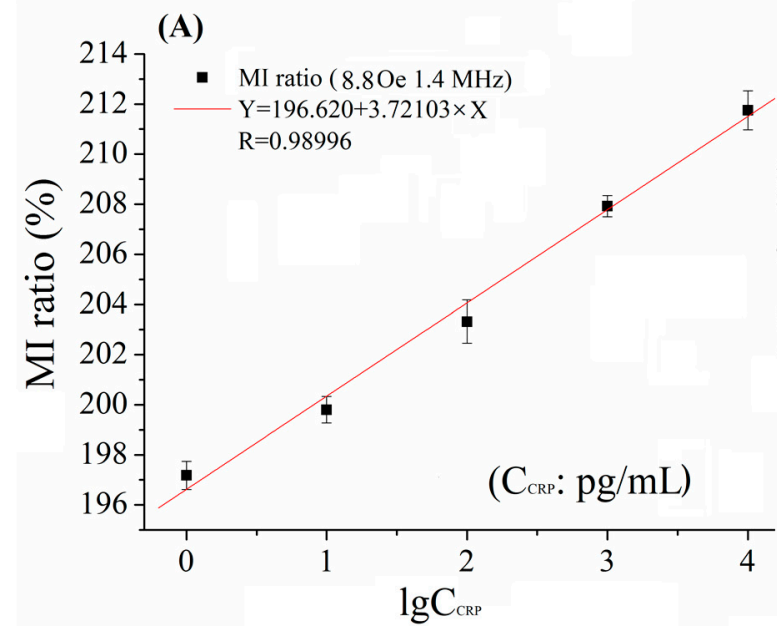

(B)

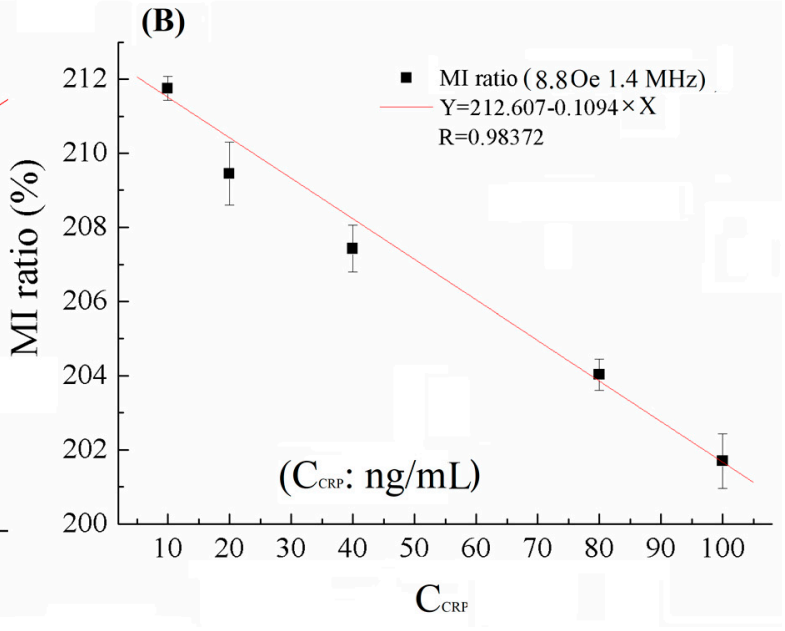

Figure 3. The relationship of MI ratio versus (A) low CRP concentrations and (B) high CRP concentrations at $\mathrm{f}=1.4 \mathrm{MHz}$ and $\mathrm{H}_{\mathrm{ex}}=8.8 \mathrm{Oe}$.

The linearity between the MI response signals and CRP concentrations with the range of $1 \mathrm{pg} / \mathrm{mL}-10 \mathrm{ng} / \mathrm{mL}$, is represented under 8.8 Oe and $1.4 \mathrm{MHz}$ by the fitting form in base-10 logarithms. As can be seen clearly from Figure 3A, 5 points locate near the curve and $R=0.98996$ is very close to 1; we can say that the MI response has a good linear relationship with the CRP concentrations. However, the MI ratio began to fall down from 218 to $202 \%$ with the change of concentration from $10 \mathrm{ng} / \mathrm{mL}$ to $100 \mathrm{ng} / \mathrm{mL}$, as can be seen in Figure S3. The linearity was also tested in this concentration range, displaying a statistical curve fitted by the linear regression. Five points locate near the curve and $R=0.98372$ is very close to 1 , as shown in Figure 3B. Therefore, lower and upper limitations of detection were $1 \mathrm{pg} / \mathrm{mL}$ and $100 \mathrm{ng} / \mathrm{mL}$, respectively.

In our previous work [25], we found that Dynabeads (conjugated $10 \mathrm{ng} / \mathrm{mL}$ biomarkers) on the surface of the element were nearly magnetically saturated. The high concentration of Dynabeads had caused the high-density clusters of Dynabeads, the interaction between beads was obvious, the whole $\mathrm{H}_{\text {stray }}$ attenuated, and the added value of the MI was reduced. A similar result on $\mathrm{Mb}$ concentration $\left(\mathrm{C}_{\mathrm{Mb}}\right)$ detection was obtained in the detection region 2, as shown in Figure 4. However, 
the linear detection ranges were $0.1 \mathrm{pg} / \mathrm{mL}-1 \mathrm{ng} / \mathrm{mL}$ and $1 \mathrm{n} / \mathrm{mL}-80 \mathrm{ng} / \mathrm{mL}$ for $\mathrm{Mb}$. From Figures 3 and 4, we observed the overlap MI value in low concentration and high concentration for CRP and $\mathrm{Mb}$. Therefore, dual-measurement for the same CBs sample would be better by using the designed MI-based bio-sensing system. Firstly, we can measure the sample with original concentration, and then measure the sample with decreased concentration by mixing with a buffer (e.g., in a ratio of 1:1). Then the region of concentration of the sample can be pinpointed depending on the trend of the MI ratio.
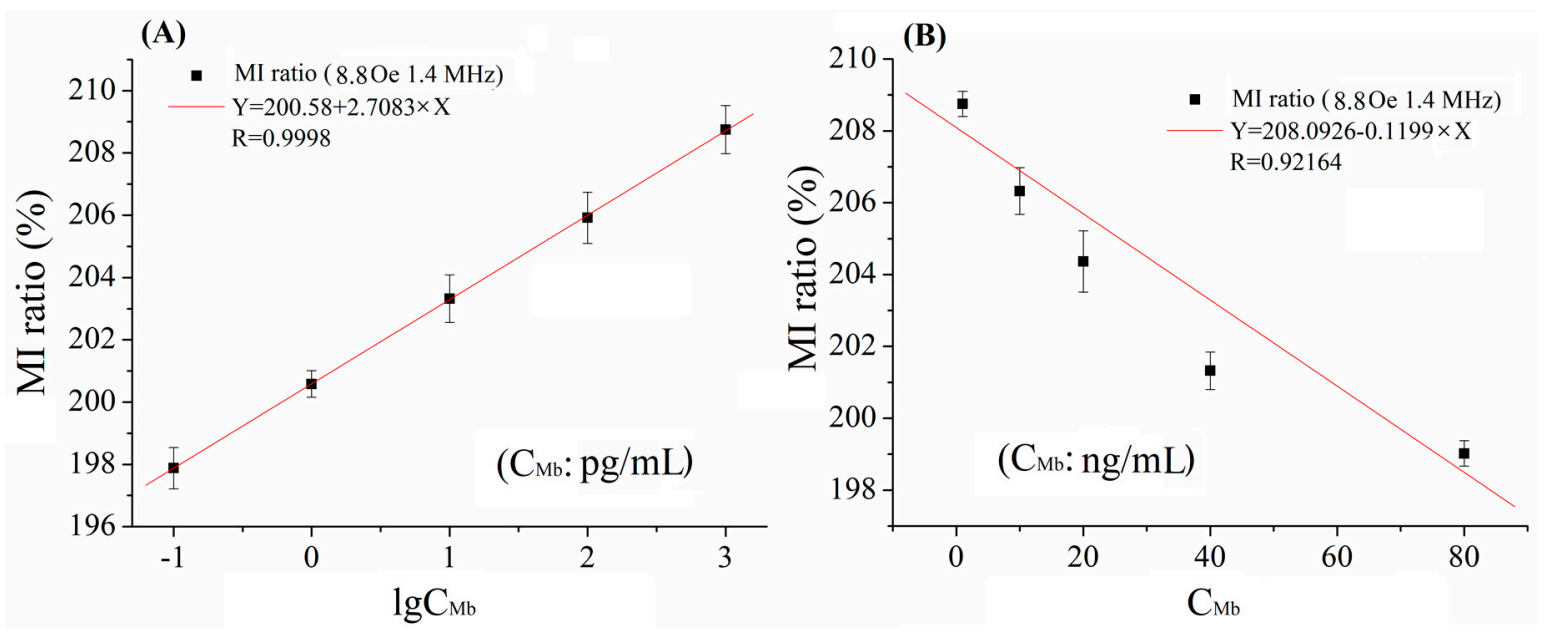

Figure 4. The relationship of MI ratio versus (A) low $\mathrm{Mb}$ concentrations and (B) high $\mathrm{Mb}$ concentrations at $\mathrm{f}=1.4 \mathrm{MHz}$ and $\mathrm{H}_{\mathrm{ex}}=8.8 \mathrm{Oe}$.

Sensitivity and specificity are two major factors to assess the practicality of immunosensors. In addition to the above sensitivity analysis, the specificity test of the MI-based bio-analytical system was performed by interfering antigen CEA. The single interfering antigen solution $(0.1 \mathrm{pg} / \mathrm{mL}$ CEA) and four mixture antigen solutions $(0.1 \mathrm{pg} / \mathrm{mL}$ CEA $+0.1 \mathrm{pg} / \mathrm{mL} \mathrm{Mb}, 0.1 \mathrm{pg} / \mathrm{mL}$ CEA $+100 \mathrm{ng} / \mathrm{mL}$ CRP, $0.1 \mathrm{pg} / \mathrm{mL} \mathrm{Mb}+100 \mathrm{ng} / \mathrm{mL}$ CRP and $0.1 \mathrm{pg} / \mathrm{mL}$ CEA + $0.1 \mathrm{pg} / \mathrm{mL} \mathrm{Mb}+100 \mathrm{ng} / \mathrm{mL}$ CRP) were infused into the MR-MFD by syringe pump, respectively. The MI response was observed in controlled region 0 and detection regions 1 and 2, with a specific antigen-antibody reaction. The MI responses of the multilayered element under varying regions are shown in Figure 5. When $0.1 \mathrm{pg} / \mathrm{mL}$ CEA antigen solution was injected into the MR-MFD, there was no sharp difference for the MI ratio between control region 0 and detection region $1 \& 2$. An exclusive significant increase in the MI ratio was discovered in detection region 2 (with injecting the $\mathrm{CEA}+\mathrm{Mb}$ antigens mixture solution) or in the detection region 1 (with injecting the CEA + CRP antigens mixture solution). However, significant variation of MI appeared simultaneously in detection region 1 and detection region 2 for $\mathrm{CRP}+\mathrm{Mb}$ and $\mathrm{CEA}+\mathrm{Mb}+$ CRP. The results indicated the selective binding of CRP in detection region 1 to the CRP antibody and $\mathrm{Mb}$ in detection region 2 to the $\mathrm{Mb}$ antibody. Thus, it illustrates the good specificity of the MI-based magnetic immunoassay for the detection of $\mathrm{Mb}$ and CRP. In view of the results of detection limit, we infused the mixed antigen $(0.1 \mathrm{pg} / \mathrm{mL}$ CRP $+0.1 \mathrm{pg} / \mathrm{mL} \mathrm{Mb}$ or $100 \mathrm{ng} / \mathrm{mL} \mathrm{CRP}+100 \mathrm{ng} / \mathrm{mL} \mathrm{Mb})$ into the MR-MFD, the same result was almost obtained like that in Figure 5 (Mb single antigen and CRP single antigen). So, in theory the detection limit for biomarkers is logical. The relative standard deviation (RSD) of $0.34 \%$ is obtained by performing 6 independent measurements (one time every ten minutes) on $0.1 \mathrm{pg} / \mathrm{mL} \mathrm{Mb}$ under the same testing conditions as shown in Figure 6, indicating an acceptable reproducibility of the magnetic immunoassay. The stability capability test was repeated in different time (The corresponding time is 1 st, 5 th, 10th, 15th, 20th days, respectively). The high stability of the MI sensor contributes to the reliability of measurement results. The same reproducibility and stability test was performed on $100 \mathrm{ng} / \mathrm{mL}$ CRP. The RSD of the 6 independent assay results 
corresponded approximately to $0.648 \%$ and indicated the satisfactory reproducibility of the presented method. The results of the stability capability test confirm the stability of the MI element.

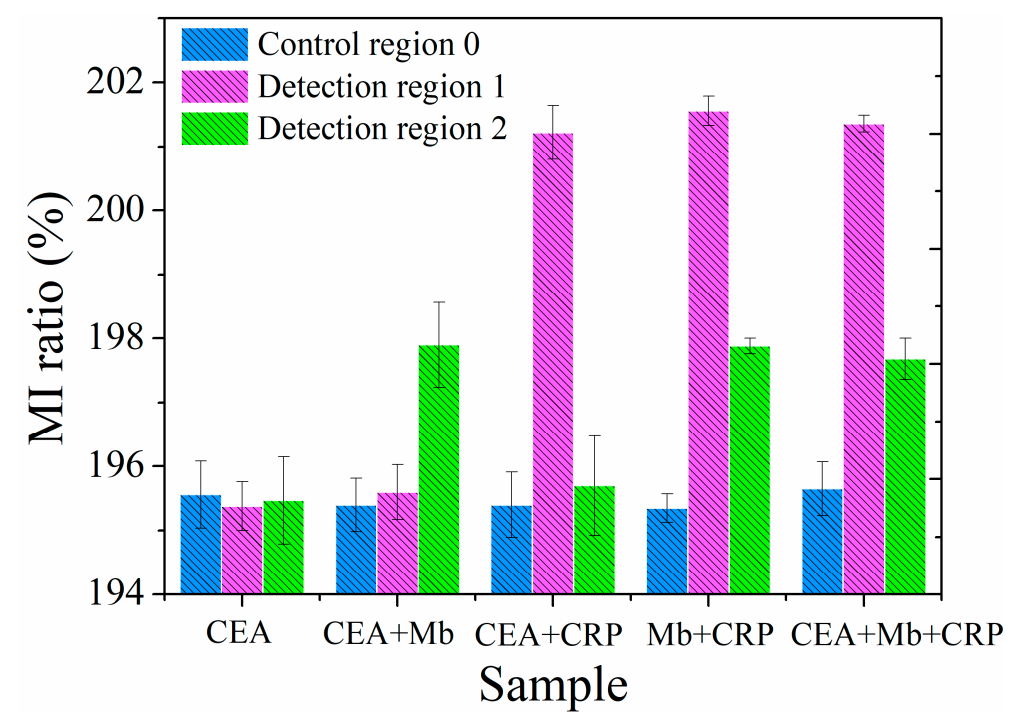

Figure 5. MI responses for the specificity test on $\mathrm{CRP}$ and $\mathrm{Mb}$; single CEA antigen solution and four antigens mixture solution ( $\mathrm{CEA}+\mathrm{Mb} ; \mathrm{CEA}+\mathrm{CRP} ; \mathrm{CRP}+\mathrm{Mb}, \mathrm{CEA}+\mathrm{Mb}+\mathrm{CRP}$ ) were injected into the MR-MFD in turn.

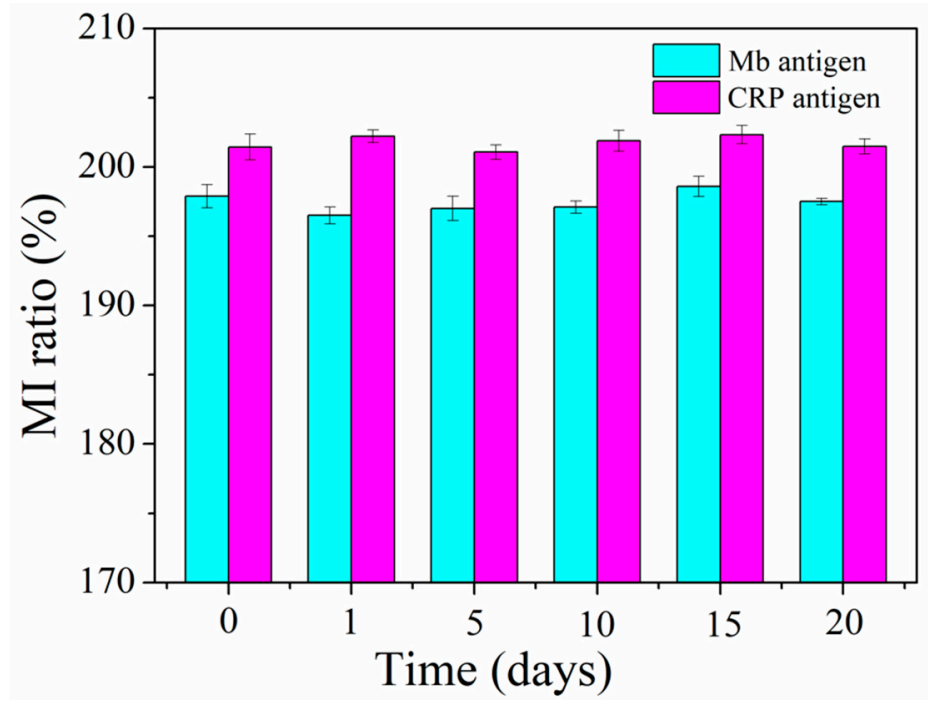

Figure 6. Stability test of the MI-based bio-analytic system in $0.1 \mathrm{pg} / \mathrm{mL} \mathrm{Mb}$ and $100 \mathrm{ng} / \mathrm{mL} \mathrm{CRP.}$

The detection limit of $1 \mathrm{ng} / \mathrm{mL}$ for CRP and $0.5 \mathrm{ng} / \mathrm{mL}$ for $\mathrm{Mb}$ was achieved by using an integrated ribbon-based MI biosensing system in our previous work [47,48]. In this work, the fabricated multilayered thin film MI sensitive element possesses a lower minimum detectable concentration of $1 \mathrm{pg} / \mathrm{mL}$ for CRP detection and $0.1 \mathrm{pg} / \mathrm{mL}$ for the $\mathrm{Mb}$ detection case. This can be attributed to the higher MI sensitivity of the multilayered thin film element. Although a lower detection limit of $0.029 \mathrm{pg} / \mathrm{mL}$ for CRP can be reached by applying a $\mathrm{NH}_{2}-\mathrm{Ni}-\mathrm{MOF}$ electrocatalysts method [49] and detection limit is $0.01 \mathrm{pg} / \mathrm{mL}$ for $\mathrm{Mb}$ using an Au-WS $\mathrm{W}_{2}$ nanohybrid based SERS aptasensor [50], utilization of the MRBAS results in ultrasensitive combined detection of CBs, $\mathrm{Mb}$ and CRP. Bio-magnetic detection has recently become a focus of interest for researchers because of its high sensitivity, versatile diagnostic methods, convenient processes, high accuracy and low cost. 
The detection limit with $0.01 \mathrm{pg} / \mathrm{mL}$ was considered more adequate for the quantification of $\mathrm{Mb}$ in clinical diagnostics. So, we will attempt to design more complex MR-MFD for ultrasensitive simultaneous detection of two, three or four biomarkers using the bio-magnetic measurement system in the future. Firstly, we are required to fabricate the higher sensitive MI element and MI element array by MEMS technology. Then, patterned microfluidic channel and magnetic nanoparticles labels will be considered for detection of CBs. Finally, the integrated MI-based biosensing system may be adopted.

\section{Conclusions}

In summary, ultrasensitive simultaneous detection of cardiac biomarkers $\mathrm{Mb}$ and CRP was achieved by the design and development of the MR MI-based bio-analytic system. The magnetic labels and double antibody sandwiched immunoassays were used for the measurements. The multilayered thin film MI element and MFD were manufactured by microfabrication techniques. The lower detection limits with $1 \mathrm{pg} / \mathrm{mL}$ for CRP and $0.1 \mathrm{pg} / \mathrm{mL}$ for $\mathrm{Mb}$ were obtained. The linear detection range contained a low concentration detection area and a high concentration detection area, which were $1 \mathrm{pg} / \mathrm{mL}-10 \mathrm{ng} / \mathrm{mL}, 10-100 \mathrm{ng} / \mathrm{mL}$ for CRP, and $0.1 \mathrm{pg} / \mathrm{mL}-1 \mathrm{ng} / \mathrm{mL}, 1 \mathrm{n} / \mathrm{mL}-80 \mathrm{ng} / \mathrm{mL}$ for $\mathrm{Mb}$, respectively. The methodology presented here is promising for multi-analyte bio-magnetic detection of biocomponents (Troponin, CK-MB, AFP, CEA) and other biomarkers using MI-based biosensing system.

Supplementary Materials: The following are available online at http:/ / www.mdpi.com/1424-8220/18/6/1765/ s1, Figure S1: Fabrication steps of the MI element, Figure S2: Field dependence of MI responses under the low concentration of CRP antigen (a) full view (b) partial enlargement, Figure S3: Field dependence of MI responses under the high concentration of CRP antigen (a) full view (b) partial enlargement, Figure S4: SEM characterizations CRP-conjugated Dynabeads at the concentration of $10 \mathrm{ng} / \mathrm{mL}$ (A) and SEM characterizations Mb-conjugated Dynabeads at the concentration of $10 \mathrm{ng} / \mathrm{mL}$ (B).

Author Contributions: Zhen Yang and Yongsong Luo conceived and designed the experiments; Pengfei Guo and Chong Lei contributed to the fabrication of the sensors; Huanhuan Wang and Yuanyuan Ding performed the biological test and analyzed the data; Zhen Yang performed some experiments and wrote this paper.

Funding: This research was funded by the National Natural Science Foundation of China (51602276, 61273065), Natural Science Foundation of Henan Province (162300410233), Nanhu Scholars Program for Young Scholars of XYNU, Major Pre-research Program of XYNU (2016-ZDYY-132, 2017-ZDYY-178), Start-up research grant for new faculty of XYNU (No. 16055).

Acknowledgments: The authors are grateful to the Key Laboratory of Microelectronics and Energy of Henan Province of Xinyang Normal University of China, Henan Administration of Foreign Experts Affairs, the Analytical and Testing Center in Shanghai Jiao Tong University, the Center for Advanced Electronic Materials and Devices in Shanghai Jiao Tong University.

Conflicts of Interest: The authors declare no conflict of interest.

\section{References}

1. Lee, W.B.; Chen, Y.H.; Lin, H.I.; Shiesh, S.C.; Lee, G.B. An integrated microfluidic system for fast, automatic detection of C-reactive protein. Biosens. Bioelectron. 2009, 24, 3091-3096. [CrossRef]

2. Kushner, I.; Sehgal, A.R. Is high-sensitivity C-reactive protein an effective screening test for cardiovascular risk? Arch. Intern. Med. 2002, 162, 867-869. [CrossRef] [PubMed]

3. Black, S.; Kushner, I.; Samols, D. C-reactive protein. J. Biol. Chem. 2004, 47, 48487-48490. [CrossRef] [PubMed]

4. Qureshi, A.; Gurbuz, Y.; Niazi, J.H. Biosensors for cardiac biomarkers detection: A review. Sens. Actuators B Chem. 2012, 171, 62-76. [CrossRef]

5. Wang, Q.; Liu, F.; Yang, X.H.; Wang, K.M.; Wang, H.; Deng, X. Sensitive point-of-care monitoring of cardiac biomarker myoglobin using aptamer and ubiquitous person $\mu$ al glucose meter. Biosens. Bioelectron. 2015, 64, 161-164. [CrossRef] [PubMed]

6. Sallach, S.M.; Nowak, R.; Hudson, M.P.; Tokarski, G.; Khoury, N.; Tomlanovich, M.C.; Jacobsen, G.; de Lemos, J.A.; McCord, J. A Change in Serum Myoglobin to Detect Acute Myocardial Infarction in Patients with Normal Troponin I Levels. Am. J. Cardiol. 2004, 94, 864-867. [CrossRef] [PubMed] 
7. Meyer, M.H.F.; Hartmann, M.; Krgoldse, H.J.; Blankenstein, G.; Mueller-Chorus, B.; Oster, J.; Miethe, P.; Keusgen, M. CRP determination based on a novel magnetic biosensor. Biosens. Bioelectron. 2007, 22, 973-979. [CrossRef] [PubMed]

8. Baselt, D.R.; Lee, G.U.; Natesan, M.; Metzger, S.W.; Sheehan, P.E.; Colton, R.J. A biosensor based on magnetoresistance technology. Biosens. Bioelectron. 1998, 13, 731-739. [CrossRef]

9. Gnedenko, O.V.; Mezentsev, Y.V.; Molnar, A.A.; Lisitsa, A.V.; Ivanov, A.S.; Archakov, A.I. Highly sensitive detection of human cardiac myoglobin using a reverse sandwich immunoassay with a gold nanoparticle-enhanced surface plasmon resonance biosensor. Anal. Chim. Acta 2013, 759, 105-109. [CrossRef] [PubMed]

10. Shorie, M.; Kumar, V.; Sabherwal, P.; Ganguli, A.K. Carbon quantum dots-mediated direct fluorescence assay for the detection of cardiac marker myoglobin. Curr. Sci. 2015, 108, 1595-1596.

11. Yang, Y.N.; Lin, H.I.; Wang, J.H.; Shiesh, S.C.; Lee, G.B. An integrated microfluidic system for C-reactive protein measurement. Biosens. Bioelectron. 2009, 24, 3091-3096. [CrossRef] [PubMed]

12. Rifai, N.; Tracy, R.P.; Ridker, P.M. Clinical efficacy of an automated high-sensitivity C-reactive protein assay. Clin. Chem. 1999, 45, 2136-2141. [PubMed]

13. Xie, M.J.; Huang, H.; Hang, J.F.; Dong, Z.N.; Xiao, D.Y.; Xu, P.; Zhu, C.Y.; Xu, W.W. Evaluation of the Analytical and Clinical Performances of Time-resolved Fluoroimmunoassay for Detecting Carcinoma Antigen 50. J. Immunoass. Immunochem. 2015, 3, 265-283. [CrossRef] [PubMed]

14. Bedatty Fernandes, F.C.; Patil, A.V.; Bueno, P.R.; Davis, J.J. Optimized Diagnostic Assays Based on Redox Tagged Bioreceptive Interfaces. Anal. Chem. 2015, 87, 12137-12144. [CrossRef] [PubMed]

15. Ren, X.H.; Zhang, Y.; Sun, Y.Q.; Gao, L.L. Development of Electrochemical Impedance Immunosensor for Sensitive Determination of Myoglobin. Int. J. Electrochem. Sci. 2017, 12, 7765-7776. [CrossRef]

16. Chiriac, H.; Herea, D.D.; Corodeanu, S. Microwire array for giant magnetoimpedance detection of magnetic particles for biosensor prototype. J. Magn. Magn. Mater. 2007, 311, 425-428. [CrossRef]

17. Kurlyandskaya, G.V.; Levit, V.I. Advanced materials for drug delivery and biosensors based on magnetic label detection. Mater. Sci. Eng. C 2007, 27, 495-503. [CrossRef]

18. Beach, R.S.; Berkowitz, A.E. Sensitive field-and frequency-dependent impedance spectra of amorphous FeCoSiB wire and ribbon. J. Appl. Phys. 1994, 76, 6209-6213. [CrossRef]

19. Kraus, L. GMI modelling and material optimization. Sens. Actuators A 2003, 106, 187-194. [CrossRef]

20. Nishibe, Y.; Ohta, N.; Tsukada, K.; Yamadera, H.; Nomomura, Y.; Mohri, K.; Uchiyama, T. Sensing of passing vehicles using a lane marker on road with built-in thin film MI sensor and power source. IEEE Trans. Veh. Technol. 2004, 53, 1827-1834. [CrossRef]

21. Wang, T.; Yang, Z.; Lei, C.; Lei, J.; Zhou, Y. An integrated giant magnetoimpedance biosensor for detection of biomarker. Biosens. Bioelectron. 2014, 58, 338-344. [CrossRef] [PubMed]

22. Blyakhman, F.A.; Safronov, A.P.; Zubarev, A.Y.; Shklyar, T.F.; Makeyev, O.G.; Makarova, E.B.; Melekhin, V.V.; Larrañaga, A.; Kurlyandskaya, G.V. Polyacrylamide ferrogels with embedded maghemite nanoparticles for biomedical engineering. Results Phys. 2017, 7, 3624-3633. [CrossRef]

23. Blyakhman, F.A.; Buznikov, N.A.; Sklyar, T.F.; Safronov, A.P.; Golubeva, E.V.; Svalov, A.V.; Sokolov, S.Y.; Melnikov, G.Y.; Orue, I.; Kurlyandskaya, G.V. Mechanical, Electrical and Magnetic Properties of Ferrogels with Embedded Iron Oxide Nanoparticles Obtained by Laser Target Evaporation: Focus on Multifunctional Biosensor Applications. Sensors 2018, 18, 872. [CrossRef] [PubMed]

24. Kurlyandskaya, G.V.; Fernandez, E.; Safronov, A.P.; Blyakhman, F.A.; Svalov, A.V.; Burgoa Beitia, A.; Beketov, I.V. Magnetoimpedance biosensor prototype for ferrogel detection. J. Magn. Magn. Mater. 2017, 441, 650-655. [CrossRef]

25. Wang, T.; Zhou, Y.; Lei, C.; Lei, J.; Yang, Z. Development of an ingenious method for determination of Dynabeads protein A based on a giant magnetoimpedance sensor. Sens. Actuators B Chem. 2013, 186, 727-733. [CrossRef]

26. Safronov, A.P.; Mikhnevich, E.A.; Lotfollahi, Z.; Blyakhman, F.A.; Sklyar, T.F.; Larrañaga Varga, A.; Medvedev, A.I.; Fernández Armas, S.; Kurlyandskaya, G.V. Polyacrylamide ferrogels with magnetite or strontium hexaferrite: Next step in the development of soft biomimetic matter for biosensor applications. Sensors 2018, 18, 257. [CrossRef] [PubMed] 
27. Yang, Z.; Liu, Y.; Lei, C.; Sun, X.C.; Zhou, Y. Ultrasensitive detection and quantification of E. coli O157:H7 using a giant magnetoimpedance sensor in an open-surface microfluidic cavity covered with an antibody-modified gold surface. Microchim. Acta 2016, 183, 1831-1837. [CrossRef]

28. Wang, T.; Zhou, Y.; Lei, C.; Luo, J.; Xie, S.R.; Pu, H.Y. Magnetic impedance biosensor: A review. Biosens. Bioelectron. 2017, 90, 418-435. [CrossRef] [PubMed]

29. Pearson, T.A.; Mensah, G.A.; Alexander, R.W.; Anderson, J.L.; Cannon, R.O.; Criqui, M.; Fadl, Y.Y.; Fortmann, S.P.; Hong, Y.; Myers, G.L.; et al. Markers of Inflammation and Cardiovascular Disease. Circulation 2003, 107, 499-511. [CrossRef] [PubMed]

30. Apple, F.S.; Murakami, M.M.; Pearce, L.A.; Herzog, C.A. Multi-Biomarker Risk Stratification of N-Terminal Pro-B-Type Natriuretic Peptide, High-Sensitivity C-Reactive Protein, and Cardiac Troponin T and I in End-Stage Renal Disease for All-Cause Death. Clin. Chem. 2004, 50, 2279-2285. [CrossRef] [PubMed]

31. Yu, X.; Xia, H.S.; Sun, Z.D.; Lin, Y.; Wang, K.; Yu, J.; Tang, H.; Pang, D.W.; Zhang, Z.L. On-chip dual detection of cancer biomarkers directly in serum based on self-assembled magnetic bead patterns and quantum dots. Biosens. Bioelectron. 2013, 41, 129-136. [CrossRef] [PubMed]

32. Han, K.N.; Li, C.A.; Seong, G.H. Microfluidic Chips for Immunoassays. Annu. Rev. Anal. Chem. 2013, 6, 119-141. [CrossRef] [PubMed]

33. Maeng, J.H.; Lee, B.C.; Ko, Y.J.; Cho, W.; Ahn, Y.; Cho, N.G.; Lee, S.H.; Hwang, S.Y. A novel microfluidic biosensor based on an electrical detection system for alpha-fetoprotein. Biosens. Bioelectron. 2008, 23, 1319-1325. [CrossRef] [PubMed]

34. Wu, J.D.; Dong, M.L.; Santos, S.; Rigatto, C.; Liu, Y.; Lin, F. Lab-on-a-Chip platforms for detection of cardiovascular disease and cancer biomarkers. Sensors 2017, 17, 2934. [CrossRef] [PubMed]

35. Lian, J.; Zhou, W.W.; Shi, X.Z.; Gao, Y.H. Development of Integrated Microfluidic Magnetic Biosensor for Multi-biomarker Detection. Chin. J. Anal. Chem. 2013, 9, 1302-1307. [CrossRef]

36. Chen, L.; Zhou, Y.; Zhou, Z.M.; Ding, W. Giant magnetoimpedance effects in patterned Co-based ribbons with a meander structure. Phys. Status Solidi (a) 2009, 206, 1594-1598. [CrossRef]

37. Chen, L.; Zhou, Y.; Zhou, Z.M.; Ding, W. Enhancement of magnetoimpedance effect in Co-based amorphous ribbon with a meander structure. Phys. Status Solidi (a) 2010, 207, 448-451. [CrossRef]

38. Rivero, M.A.; Maicas, M.; Lopez, E.; Aroca, C.; Sanchez, M.C.; Sanchez, P.J. Influence of the sensor shape on permalloy/Cu/permalloy magnetoimpedance. Magn. Magn. Mater. 2003, 254, 636-640. [CrossRef]

39. Morikawa, T.; Nishibe, Y.; Yamadera, H.; Nonomura, Y.; Takeuchi, M.; Sakata, J.; Taga, Y. Enhancement of giant magneto-impedance in layered film by insulator separation. IEEE Trans. Magn. 1996, 32, 4965-4967. [CrossRef]

40. Lodewijk, K.J.; Fernandez, E.; Garcia-Arribas, A.; Kurlyandskaya, G.V.; Lepalovskij, V.N.; Safronov, A.P.; Kooi, B.J. Magnetoimpedance of thin film meander with composite coating layer containing Ni nanoparticles. J. Appl. Phys. 2014, 115, 17A323. [CrossRef]

41. Wang, T.; Lei, C.; Lei, J.; Yang, Z.; Zhou, Y. Preparation of meander thin-film microsensor and investigation the influence of structural parameters on the giant magnetoimpedance effect. Appl. Phys. A 2012, 109, 205-211. [CrossRef]

42. Park, J.Y.; Allen, M.G. Integrated electroplated micromachined magnetic devices using low temperature fabrication processes. IEEE Trans. Electron. Packag. Manuf. 2000, 23, 48-55. [CrossRef]

43. Wang, T.; Zhou, Y.; Lei, C.; Lei, J.; Yang, Z. Ultrasensitive detection of Dynabeads protein A using the giant magnetoimpedance effect. Microchim. Acta 2013, 180, 1211-1216. [CrossRef]

44. Miller, M.M.; Prinz, G.A.; Cheng, S.F.; Bounnak, S. Detection of a micron-sized magnetic sphere using a ring-shaped anisotropic magnetoresistance-based sensor: A model for a magnetoresistance-based biosensor. Appl. Phys. Lett. 2002, 81, 2211-2213. [CrossRef]

45. Ferreira, H.A.; Graham, D.L.; Freitas, P.P.; Cabral, J.M.S. Biodetection using magnetically labeled biomolecules and arrays of spin valve sensors. J. Appl. Phys. 2002, 93, 7281-7286. [CrossRef]

46. Besse, P.A.; Boero, G.; Demierre, M.; Pott, V.; Popovic, R. Detection of single magnetic microbead using a miniaturized silicon Hall sensor. Appl. Phys. Lett. 2002, 80, 4199-4201. [CrossRef]

47. Yang, Z.; Liu, Y.; Lei, C.; Sun, X.C.; Zhou, Y. A flexible giant magnetoimpedance-based biosensor for the determination of the biomarker C-reactive protein. Microchim. Acta 2015, 182, 2411-2417. [CrossRef]

48. Yang, Z.; Wang, H.H.; Dong, X.W.; Yan, H.L.; Lei, C.; Luo, Y.S. Giant magnetoimpedance based immunoassay for cardiac biomarker myoglobin. Anal. Methods 2017, 9, 3636-3642. [CrossRef] 
49. Shorie, M.; Kumar, V.; Kaur, H.; Singh, K.; Tomer, V.K.; Sabherwal, P. Plasmonic DNA hotspots made from tungsten disulfide nanosheets and gold nanoparticles for ultrasensitive aptamer-based SERS detection of myoglobin. Microchim. Acta 2018, 185, 158-165. [CrossRef] [PubMed]

50. Wang, Z.; Dong, P.; Sun, Z.X.; Sun, C.; Bu, H.Y.; Han, J.; Chen, S.P.; Xie, G. $\mathrm{NH}_{2}-\mathrm{Ni}$-MOF electrocatalysts with tunable size/morphology for ultrasensitive C-reactive protein detection via an aptamer binding induced DNA walker-antibody sandwich assay. J. Mater. Chem. B. 2018, 6, 2426-2431. [CrossRef]

C 2018 by the authors. Licensee MDPI, Basel, Switzerland. This article is an open access article distributed under the terms and conditions of the Creative Commons Attribution (CC BY) license (http:/ / creativecommons.org/licenses/by/4.0/). 